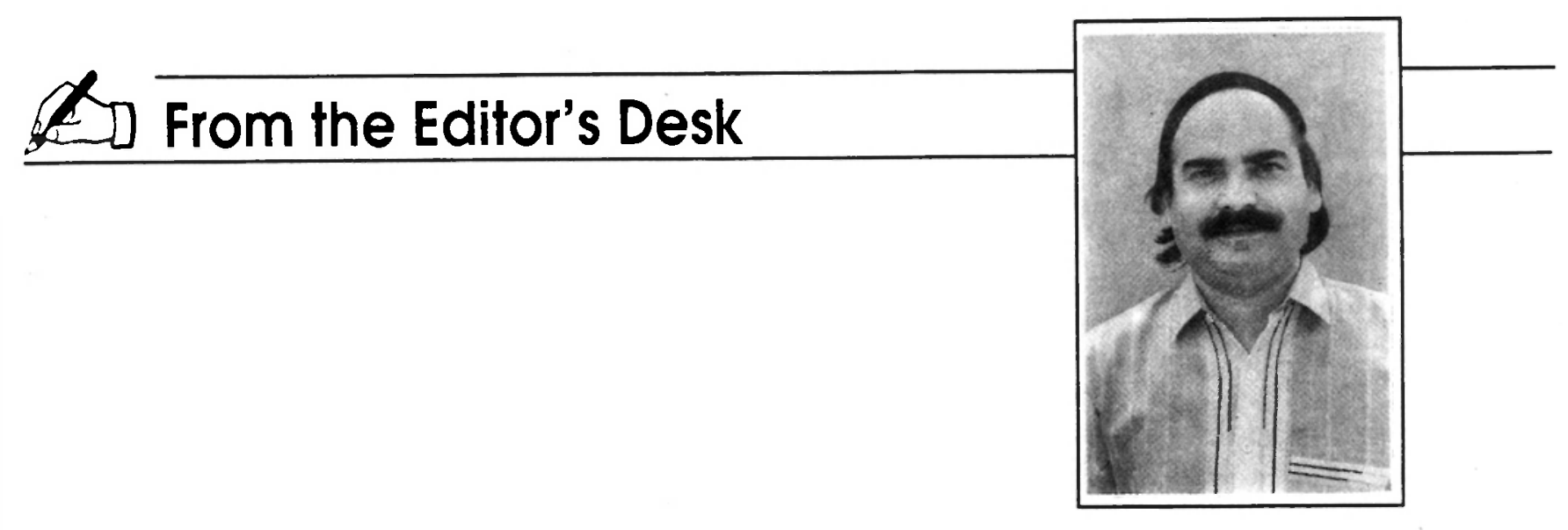

Dear Reader,

Allow me to quote Mr. Advani, Editor of Business India, "How many Indian Companies are technology driven".

Some of my readers may wonder why we need to ask this question! After all, we have the third largest pool of scientific personnel. Everyday we come to know of the companies that claim to have modernized by adopting latest technology or enlisted them in some quality standards or other to endure better customer service. But, the fact remains that this is less than half of the story.

It is fully established that years of licensing quota raj has stultified the growth and the technological innovation in Indian engineering industry. After a close look at the industries, we see that the Companies have imported the technology from the overseas and negligible efforts are being made to develop the product / process where real engineering skills are required.

Time has now come to update our knowledge base so that we can be internationally competitive.

You are aware that the gala event in Indian welding scenario, National Welding Seminar is scheduled to take place at Jamshedpur from 24th to 26th November, 1994 and I was informed that the most of internationally acknowledged organizations are going to participate in this seminar. I am sure, this will be the right opportunity for us to enrich our knowledge and skill by way of participating in the above Seminar.

I welcome all of you to take active interest in NWS, 1994 to make this event a great success.

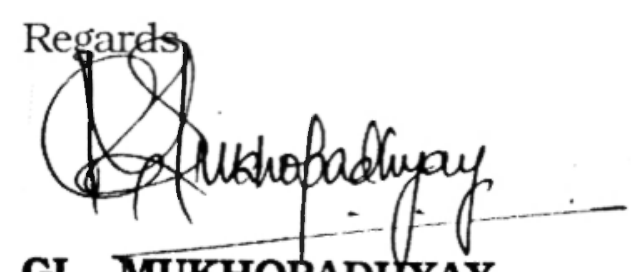

\title{
GL. MUKHOPADHYAY
}

